\title{
SN Term Type
}

National Cancer Institute

\section{Source}

National Cancer Institute. SN Term Type. NCI Thesaurus. Code C45779.

The $\mathrm{NCl}$ term type designation for a chemical structure name. 